\title{
INDICADORES FEDERATIVOS
}

\section{INDICADORES FISCAIS DOS ESTADOS DA FEDERAÇÃO NO PERÍODO 2019-2020}

\section{INDICADOR DE ENDIVIDAMENTO}

Representa a parcela da dívida pública consolidada (obrigaçôes financeiras) na receita corrente líquida (RCL) (somatório da arrecadação tributária menos as transferências constitucionais e legais). A tabela 1 apresenta os valores para setembro de 2019 e março e setembro de 2020, assim como a variaçáo entre esses períodos. Entre setembro de 2019 e setembro de 2020, o endividamento estadual caiu em todas as regiōes, à exceção do Sudeste, onde houve um pequeno aumento de $1,4 \%$. Pela ordem, os maiores aumentos relativos foram observados nas dívidas dos estados de Tocantins, Rio Grande do Norte, Pará e Ceará. Os estados com os maiores estoques de dívidas em setembro de 2020 são, por ordem decrescente, Rio de Janeiro, Rio Grande do Sul, Minas Gerais e São Paulo.

TABELA 1

Endividamento: dívida pública consolidada/ $\mathrm{RCL}^{1}$

(Em \%)

\begin{tabular}{|c|c|c|c|c|c|}
\hline & \multirow{2}{*}{$\frac{2019}{\text { Setembro }}$} & \multicolumn{2}{|c|}{2020} & \multirow{2}{*}{$\begin{array}{l}\text { Variação entre setembro } \\
\text { de } 2019 \text { e setembro de } 2020\end{array}$} & \multirow{2}{*}{$\begin{array}{c}\text { Variação entre março e } \\
\text { setembro de } 2020\end{array}$} \\
\hline & & Março & Setembro & & \\
\hline Região Norte & 21,1 & 19,5 & 9,1 & $-56,7$ & $-53,2$ \\
\hline Acre & 53,0 & 60,9 & 50,9 & $-3,8$ & $-16,4$ \\
\hline Amapá & 41,1 & $-44,5$ & $-51,2$ & $-224,6$ & $-15,0$ \\
\hline Amazonas & 34,8 & 33,7 & 22,0 & $-36,8$ & $-34,6$ \\
\hline Pará & 4,7 & 9,0 & 5,8 & 22,2 & $-36,3$ \\
\hline Rondônia & 19,0 & 22,7 & 12,7 & $-33,3$ & $-44,0$ \\
\hline Roraima & $-19,4$ & $-28,5$ & $-69,4$ & $-257,7$ & $-143,5$ \\
\hline Tocantins & 26,7 & 58,3 & 45,2 & 69,2 & $-22,6$ \\
\hline Região Nordeste & 56,5 & 60,8 & 52,4 & $-7,3$ & $-13,8$ \\
\hline Alagoas & 88,2 & 97,6 & 91,6 & 3,9 & $-6,1$ \\
\hline Bahia & 61,1 & 71,9 & 66,2 & 8,3 & $-7,9$ \\
\hline Ceará & 58,8 & 70,7 & 69,3 & 17,8 & $-2,0$ \\
\hline
\end{tabular}

1. DOI: http://dx.doi.org/10.38116/brua24art24 


\begin{tabular}{|c|c|c|c|c|c|}
\hline & \multirow{2}{*}{$\begin{array}{c}2019 \\
\text { Setembro }\end{array}$} & \multicolumn{2}{|c|}{2020} & \multirow{2}{*}{$\begin{array}{l}\text { Variação entre setembro } \\
\text { de } 2019 \text { e setembro de } 2020\end{array}$} & \multirow{2}{*}{$\begin{array}{c}\text { Variação entre março e } \\
\text { setembro de } 2020\end{array}$} \\
\hline & & Março & Setembro & & \\
\hline Maranhão & 51,4 & 38,9 & 17,2 & $-66,5$ & $-55,6$ \\
\hline Paraíba & 29,4 & 26,1 & 14,3 & $-51,4$ & $-45,2$ \\
\hline Pernambuco & 56,7 & 63,8 & 57,5 & 1,4 & $-10,0$ \\
\hline Piauí & 66,4 & 51,7 & 37,4 & $-43,7$ & $-27,7$ \\
\hline Rio Grande do Norte & 18,6 & 41,0 & 24,3 & 30,4 & $-40,8$ \\
\hline Sergipe & 74,9 & 57,9 & 61,9 & $-17,3$ & 6,9 \\
\hline Região Centro-Oeste & 55,9 & 49,3 & 43,6 & $-22,1$ & $-11,7$ \\
\hline Distrito Federal & 32,9 & 30,2 & 34,5 & 5,0 & 14,4 \\
\hline Goiás & 87,8 & 82,8 & 79,9 & $-9,0$ & $-3,5$ \\
\hline Mato Grosso & 32,1 & 21,3 & 9,3 & $-71,1$ & $-56,4$ \\
\hline Mato Grosso do Sul & 69,0 & 58,8 & 42,3 & $-38,8$ & $-28,1$ \\
\hline Região Sudeste & 206,8 & 208,7 & 209,7 & 1,4 & 0,5 \\
\hline Espírito Santo & 13,6 & 11,4 & 9,9 & $-27,0$ & $-12,7$ \\
\hline Minas Gerais & 208,4 & 213,5 & 207,2 & $-0,6$ & $-3,0$ \\
\hline Rio de Janeiro & 291,4 & 309,5 & 322,8 & 10,7 & 4,3 \\
\hline São Paulo & 193,8 & 189,2 & 189,1 & $-2,4$ & $-0,1$ \\
\hline Região Sul & 120,5 & 118,6 & 116,3 & $-3,5$ & $-1,9$ \\
\hline Paraná & 36,9 & 28,0 & 24,2 & $-34,5$ & $-13,8$ \\
\hline Santa Catarina & 68,6 & 66,4 & 56,2 & $-18,1$ & $-15,4$ \\
\hline Rio Grande do Sul & 241,1 & 244,1 & 250,0 & 3,7 & 2,4 \\
\hline Total Brasil' & 128,4 & 127,8 & 122,6 & $-4,5$ & $-4,1$ \\
\hline
\end{tabular}

Fonte: Banco Central do Brasil (BCB).

Notas: ${ }^{1}$ Valores mensais da RCL acumulados em doze meses. Dados da RCL estimados com base nos relatórios de gestão fiscal dos governos estaduais. ${ }^{2}$ Refere-se à soma de todas as regiões.

Obs.: Para as três primeiras colunas numéricas, (-) é a posição credora.

\section{INDICADOR DO SERVIÇO DA DÍVIDA}

Medida da parcela das despesas com juros da dívida em relação à RCL. De maneira geral, comparando as variaçóes ocorridas em doze meses, na penúltima coluna da tabela 2 , o indicador é decrescente nas escalas estadual, regional e nacional (exceto nos estados do Rio Grande do Norte e Rio de Janeiro), refletindo a medida de suspensão do pagamento dos juros das dívidas estaduais junto à Uniáo durante o período da pandemia. Os estados de Roraima, Rondônia e Tocantins apresentaram as maiores quedas no indicador.

TABELA 2

Serviço da dívida: serviço da dívida (juros)/RCL ${ }^{1}$

$(\mathrm{Em} \%)$

\begin{tabular}{|c|c|c|c|c|c|}
\hline & \multirow{2}{*}{$\begin{array}{c}2019 \\
\text { Setembro }\end{array}$} & \multicolumn{2}{|c|}{2020} & \multirow{2}{*}{$\begin{array}{c}\text { Variação entre setembro } \\
\text { de } 2019 \text { e setembro de } 2020\end{array}$} & \multirow{2}{*}{$\begin{array}{l}\text { Variação entre março } \\
\text { e setembro de } 2020\end{array}$} \\
\hline & & Março & Setembro & & \\
\hline Região Norte & 1,4 & 1,1 & 0,7 & $-54,3$ & $-41,3$ \\
\hline Acre & 3,3 & 2,8 & 3,1 & $-4,1$ & 11,2 \\
\hline Amapá & 2,4 & 2,2 & 1,1 & $-55,7$ & $-51,8$ \\
\hline Amazonas & 1,6 & 1,3 & 0,9 & $-42,6$ & $-28,7$ \\
\hline Pará & 0,7 & 0,5 & 0,4 & $-38,2$ & $-22,3$ \\
\hline Rondônia & 1,7 & 1,2 & 0,5 & $-69,0$ & $-58,4$ \\
\hline
\end{tabular}




\begin{tabular}{|c|c|c|c|c|c|}
\hline & \multirow{2}{*}{$\begin{array}{c}2019 \\
\text { Setembro }\end{array}$} & \multicolumn{2}{|c|}{2020} & \multirow{2}{*}{$\begin{array}{l}\text { Variação entre setembro } \\
\text { de } 2019 \text { e setembro de } 2020\end{array}$} & \multirow{2}{*}{$\begin{array}{l}\text { Variação entre março } \\
\text { e setembro de } 2020\end{array}$} \\
\hline & & Março & Setembro & & \\
\hline Roraima & 0,6 & 0,2 & 0,2 & $-70,3$ & $-3,3$ \\
\hline Tocantins & 1,4 & 0,8 & 0,5 & $-63,5$ & $-39,6$ \\
\hline Região Nordeste & 2,6 & 2,3 & 1,9 & $-29,3$ & $-18,8$ \\
\hline Alagoas & 6,2 & 5,6 & 3,9 & $-36,5$ & $-29,1$ \\
\hline Bahia & 2,4 & 2,1 & 2,0 & $-16,2$ & $-1,1$ \\
\hline Ceará & 2,9 & 2,8 & 2,8 & $-6,2$ & $-2,5$ \\
\hline Maranhão & 2,4 & 1,9 & 1,4 & $-43,0$ & $-25,5$ \\
\hline Paraíba & 1,1 & 0,9 & 0,6 & $-44,6$ & $-36,5$ \\
\hline Pernambuco & 3,0 & 2,6 & 1,8 & $-40,9$ & $-32,1$ \\
\hline Piauí & 2,9 & 2,3 & 1,2 & $-57,4$ & $-46,8$ \\
\hline Rio Grande do Norte & 0,7 & 0,8 & 0,9 & 34,4 & 24,3 \\
\hline Sergipe & 2,5 & 2,2 & 1,6 & $-34,0$ & $-25,3$ \\
\hline Região Centro-Oeste & 3,6 & 3,2 & 2,8 & $-22,3$ & $-11,0$ \\
\hline Distrito Federal & 1,1 & 1,0 & 0,7 & $-33,7$ & $-26,5$ \\
\hline Goiás & 6,7 & 6,2 & 6,6 & $-1,0$ & 6,5 \\
\hline Mato Grosso & 2,4 & 1,8 & 1,1 & $-53,1$ & $-38,5$ \\
\hline Mato Grosso do Sul & 4,2 & 3,2 & 2,0 & $-51,5$ & $-36,9$ \\
\hline Região Sudeste & 11,6 & 10,7 & 9,3 & $-19,9$ & $-13,4$ \\
\hline Espírito Santo & 1,5 & 1,4 & 1,2 & $-22,8$ & $-15,2$ \\
\hline Minas Gerais & 12,8 & 12,1 & 10,4 & $-18,7$ & $-14,0$ \\
\hline Rio de Janeiro & 16,9 & 16,5 & 17,9 & 5,8 & 8,0 \\
\hline São Paulo & 10,1 & 8,9 & 6,5 & $-35,6$ & $-27,0$ \\
\hline Região Sul & 5,9 & 5,5 & 4,3 & $-26,1$ & $-20,9$ \\
\hline Paraná & 2,0 & 1,5 & 0,8 & $-58,5$ & $-43,7$ \\
\hline Santa Catarina & 3,3 & 2,8 & 2,0 & $-41,5$ & $-29,4$ \\
\hline Rio Grande do Sul & 11,5 & 11,3 & 9,5 & $-17,7$ & $-16,3$ \\
\hline Total Brasil ${ }^{2}$ & 7,0 & 6,4 & 5,3 & $-24,0$ & $-16,4$ \\
\hline
\end{tabular}

\section{INDICADOR DA PARCELA DO RESULTADO PRIMÁRIO QUE SERVE À DÍVIDA}

Indicador calculado pela razão entre a necessidade de financiamento (despesas não financeiras menos as receitas não financeiras) e a despesa com juros da dívida. Valor positivo (negativo) significa aumento (abatimento) no estoque da dívida. Considerando os sinais dos valores em março e setembro de 2020, o resultado primário se mostrou favorável à redução do endividamento nas regiōes Norte, Nordeste, Centro-Oeste e Sudeste. Apenas na região Sul, em face dos deficit primários observados no Paraná e no Rio Grande do Sul, observou-se a predominância de aumento no estoque das dívidas estaduais. Outros estados que registraram deficit primários no período foram Piauí, Rio Grande do Norte, Sergipe e Minas Gerais. 
TABELA 3

Resultado primário que serve à dívida: necessidade de financiamento/serviço da dívida (juros) ${ }^{1}$ (Em \%)

\begin{tabular}{|c|c|c|c|c|c|}
\hline & \multirow{2}{*}{$\begin{array}{c}2019 \\
\text { Setembro }\end{array}$} & \multicolumn{2}{|c|}{2020} & \multirow{2}{*}{$\begin{array}{l}\text { Variação entre setembro } \\
\text { de } 2019 \text { e setembro de } 2020\end{array}$} & \multirow{2}{*}{$\begin{array}{l}\text { Variação entre março } \\
\text { e setembro de } 2020\end{array}$} \\
\hline & & Março & Setembro & & \\
\hline Região Norte & $-317,6$ & $-322,5$ & $-1.602,5$ & 404,5 & 396,9 \\
\hline Acre & $-202,9$ & $-231,4$ & $-541,9$ & 167,1 & 134,2 \\
\hline Amapá & $-80,2$ & $-120,3$ & $-1.105,3$ & $1.277,8$ & 818,9 \\
\hline Amazonas & $-22,3$ & $-272,1$ & $-1.570,0$ & $6.926,6$ & 477,1 \\
\hline Pará & 252,0 & 341,3 & $-511,1$ & $-302,8$ & $-249,8$ \\
\hline Rondônia & $-537,6$ & $-726,9$ & $-2.174,5$ & 304.5 & 199,2 \\
\hline Roraima & $-3.936,4$ & $-10.744,2$ & $-12.992,7$ & 230,1 & 20,9 \\
\hline Tocantins & $-954,4$ & $-363,8$ & $-2.698,7$ & 182,8 & 641,8 \\
\hline Região Nordeste & 5,7 & $-28,9$ & $-243,3$ & $-4.403,4$ & 741,8 \\
\hline Alagoas & $-67,7$ & $-62,8$ & $-62,7$ & $-7,3$ & $-0,1$ \\
\hline Bahia & 30,6 & 76,8 & $-259,0$ & $-945,1$ & $-437,2$ \\
\hline Ceará & 81,0 & 10,2 & $-62,2$ & $-176,8$ & $-708,3$ \\
\hline Maranhão & 2,2 & $-203,1$ & $-1.129,3$ & $-52.275,3$ & 456,1 \\
\hline Paraíba & $-5,2$ & $-542,3$ & $-2.889,0$ & $55.351,3$ & 432,7 \\
\hline Pernambuco & $-98,3$ & $-46,6$ & $-121,6$ & 23,7 & 160,9 \\
\hline Piauí & $-67,3$ & $-139,9$ & 312,5 & $-564,3$ & $-323,3$ \\
\hline Rio Grande do Norte & 614,1 & 542,6 & $-204,1$ & $-133,2$ & $-137,6$ \\
\hline Sergipe & 141,4 & 4,1 & 257,8 & 82,7 & $6.191,8$ \\
\hline Região Centro-Oeste & 31,8 & $-141,2$ & $-392,8$ & $-1.334,4$ & 178,3 \\
\hline Distrito Federal & 589,8 & $-321,5$ & $-247,5$ & $-142,0$ & $-23,0$ \\
\hline Goiás & 30,9 & 4,1 & $-174,7$ & $-666,0$ & $-4.378,4$ \\
\hline Mato Grosso & $-131,6$ & $-489,1$ & $-1.449,2$ & $1.001,6$ & 196,3 \\
\hline Mato Grosso do Sul & $-132,8$ & $-311,7$ & $-948,0$ & 614,0 & 204,2 \\
\hline Região Sudeste & 4,3 & $-14,6$ & $-57,7$ & $-1.432,2$ & 295,7 \\
\hline Espírito Santo & $-246,4$ & 5,6 & $-108,8$ & $-55,8$ & $-2.058,2$ \\
\hline Minas Gerais & 17,2 & 37,6 & 5,9 & $-66,0$ & $-84,4$ \\
\hline Rio de Janeiro & 44,1 & $-17,5$ & $-42,1$ & $-195,4$ & 140,3 \\
\hline São Paulo & $-23,1$ & $-41,0$ & $-113,7$ & 391,8 & 177,4 \\
\hline Região Sul & $-41,2$ & 20,5 & 25,0 & $-160,6$ & 22,1 \\
\hline Paraná & $-294,4$ & 251,7 & 301,4 & $-202,4$ & 19,8 \\
\hline Santa Catarina & $-168,8$ & $-127,1$ & $-534,6$ & 216,7 & 320,5 \\
\hline Rio Grande do Sul & 29,2 & 17,7 & 86,4 & 195,9 & 388,7 \\
\hline Total Brasil $^{2}$ & $-6,4$ & $-23,4$ & $-101,1$ & $1.486,9$ & 332,7 \\
\hline
\end{tabular}

Fonte: $\mathrm{BCB}$.

Notas: ${ }^{1}$ Valores mensais dos resultados primários e dos juros da dívida acumulados em doze meses. ${ }^{2}$ Refere-se à soma de todas as regiões.

Obs.: Para as três primeiras colunas numéricas, (-) é o superavit.

\section{4 ÍNDICE DE VULNERABILIDADE FISCAL (IVF)}

Índice ponderado dos indicadores de endividamento (peso 5), do serviço da dívida (peso 3) e de resultado primário servindo à dívida (peso 2). Esse índice é uma adaptação resumida da metodologia utilizada pelo Ministério da Fazenda (MF), entre 2012 e 2017, para a análise da capacidade de pagamento e de contrapartida para a concessão de aval e garantia da União a estados, Distrito Federal e municípios. 
Em termos gerais, no período entre setembro de 2019 e setembro de 2020, o IVF apresentou decréscimo nas regióes Norte, Nordeste, Centro-Oeste e Sudeste, e aumento na regiáo Sul. Os estados que tiveram os maiores crescimentos relativos na vulnerabilidade fiscal foram Piauí, Sergipe e Rio Grande do Sul. Os estados com as maiores reduçôes foram Santa Catarina, Amapá e Paraíba. O indicador aponta situação fiscal crítica (dada por IVF > 100) nos estados de Minas Gerais, Rio de Janeiro e Rio Grande do Sul.

\section{TABELA 4}

IVF

\begin{tabular}{|c|c|c|c|c|c|}
\hline & \multirow{2}{*}{$\begin{array}{c}2019 \\
\text { Setembro }\end{array}$} & \multicolumn{2}{|c|}{2020} & \multirow{2}{*}{$\begin{array}{c}\text { Variação entre setembro } \\
\text { de } 2019 \text { e setembro de } 2020\end{array}$} & \multirow{2}{*}{$\begin{array}{l}\text { Variação entre março } \\
\text { e setembro de } 2020\end{array}$} \\
\hline & & Março & Setembro & & \\
\hline Região Norte & $-52,6$ & $-54,4$ & $-315,7$ & 500,7 & 480,2 \\
\hline Acre & $-13,1$ & $-15,0$ & $-82,0$ & 525,0 & 447,7 \\
\hline Amapá & 5,2 & $-45,6$ & $-246,3$ & $-4.811,9$ & 439,7 \\
\hline Amazonas & 13,4 & $-37,2$ & $-302,7$ & $-2.352,5$ & 714,5 \\
\hline Pará & 52,9 & 72,9 & $-99,2$ & $-287,4$ & $-236,1$ \\
\hline Rondônia & $-97,5$ & $-133,7$ & $-428,4$ & 339,4 & 220,5 \\
\hline Roraima & $-796,8$ & $-2.163,0$ & $-2.633,2$ & 230,5 & 21,7 \\
\hline Tocantins & $-177,1$ & $-43,3$ & $-517,0$ & 191,9 & $1.092,8$ \\
\hline Região Nordeste & 30,2 & 25,3 & $-21,9$ & $-172,6$ & $-186,6$ \\
\hline Alagoas & 32,4 & 37,9 & 34,4 & 6,2 & $-9,2$ \\
\hline Bahia & 37,4 & 51,9 & $-18,1$ & $-148,4$ & $-134,8$ \\
\hline Ceará & 46,5 & 38,2 & 23,0 & $-50,5$ & $-39,8$ \\
\hline Maranhão & 26,9 & $-20,6$ & $-216,8$ & $-906,4$ & 951,4 \\
\hline Paraíba & 14,0 & $-95,1$ & $-570,5$ & $-4.175,0$ & 499,7 \\
\hline Pernambuco & 9,6 & 23,4 & 4,9 & $-48,4$ & $-78,9$ \\
\hline Piauí & 20,6 & $-1,4$ & 81,6 & 295,7 & $-5.816,1$ \\
\hline Rio Grande do Norte & 132,3 & 129,2 & $-28,4$ & $-121,5$ & $-122,0$ \\
\hline Sergipe & 66,4 & 30,4 & 83,0 & 25,0 & 172,9 \\
\hline Região Centro-Oeste & 35,4 & $-2,6$ & $-55,9$ & $-257,9$ & $2.027,8$ \\
\hline Distrito Federal & 134,7 & $-48,9$ & $-32,0$ & $-123,8$ & $-34,5$ \\
\hline Goiás & 52,1 & 44,1 & 7,0 & $-86,6$ & $-84,1$ \\
\hline Mato Grosso & $-9,6$ & $-86,6$ & $-284,9$ & $2.874,2$ & 228,8 \\
\hline Mato Grosso do Sul & 9,2 & $-32,0$ & $-167,9$ & $-1.923,2$ & 424,8 \\
\hline Região Sudeste & 107,7 & 104,6 & 96,1 & $-10,8$ & $-8,2$ \\
\hline Espírito Santo & $-42,0$ & 7,2 & $-16,4$ & -60.9 & $-327,5$ \\
\hline Minas Gerais & 111,5 & 117,9 & 107,9 & $-3,2$ & $-8,5$ \\
\hline Rio de Janeiro & 159,6 & 156,2 & 158,3 & $-0,8$ & 1,4 \\
\hline São Paulo & 95,3 & 89,1 & 73,8 & $-22,6$ & $-17,2$ \\
\hline Região Sul & 53,8 & 65,0 & 64,5 & 19,8 & $-0,9$ \\
\hline Paraná & $-39,8$ & 64,8 & 72,6 & $-282,3$ & 12,1 \\
\hline Santa Catarina & 1,6 & 8,6 & $-78,2$ & $-5.080,3$ & $-1.009,9$ \\
\hline Rio Grande do Sul & 129,9 & 129,0 & 145,1 & 11,8 & 12,5 \\
\hline Total Brasil' & 65,0 & 61,1 & 42,7 & $-34,4$ & $-30,2$ \\
\hline
\end{tabular}

Fonte: $\mathrm{BCB}$.

Nota: ${ }^{1}$ Refere-se à soma de todas as regiões.

Obs.: Situação fiscal: IVF $<10=$ ótima; $10<$ IVF $<20=$ muito boa; $20<$ IVF $<40=$ boa; $40<$ IVF $<60=$ neutra; $60<$ IVF $<80=$ fraca; $80<$ IVF $<100=$ muito fraca; IVF $>100=$ crítica. 